DOI: $10.15690 / p f . v 15 i 2.1874$

Н.В. Журкова, Н.Д. Вашакмадзе, К.В. Савостьянов, А.А. Пушков, А.Н. Нестеров, Л.С. Намазова-Баранова

Национальный медицинский исследовательский центр здоровья детей,

Москва, Российская Федерация

\title{
Недостаточность комплекса
}

\section{V дыхательной цепи митохондрий,}

\section{тип 2 (АТФ-синтазы), обусловленная}

мутациями в гене TMEM70:

\section{первое в России клиническое описание}

Контактная информация:

Журкова Наталия Вячеславовна, кандидат медицинских наук, старший научный сотрудник лаборатории молекулярной генетики и клеточной биологии ФГАУ „НМИЦ здоровья детей” Минздрава РФ

Адрес: 119991, Москва, Ломоносовский проспект, д. 2, стр. 1, тел.: +7 (499) 134-09-19, e-mail: n1972z@yandex.ru

Статья поступила: 22.02.2018 г., принята к печати: 30.04.2018 г.

Недостаточность комплекса $V$ дыхательной цепи митохондрий, тип 2, обусловленная мутациями в ядерном геноме - редкое наследственное заболевание, возникающее вследствие мутаций в гене ТМЕМ70 (трансмембранного протеина 70). С использованием технологии массового параллельного секвенирования у пациента с особенностями фенотипа, синдромом некомпактного миокарда левого желудочка и врожденным пороком сердца впервые в России в гене TMEM70 были выявлены мутации с.317-2A>G и c.578_579del, в гетерозиготном состоянии. Мутации подтверждены методом двунаправленного автоматического секвенирования.

Ключевые слова: болезни дыхательной цепи митохондрий, АТФ-6 синтетаза, комплекс $V$ дыхательной цепи митохондрий, недостаточность, некомпактный миокард левого желудочка, врожденный порок сердца, TMEM70.

(Для цитирования: Журкова Н.В, Вашакмадзе Н.Д., Савостьянов К.В, Пушков А.А., Нестеров А.Н., НамазоваБаранова Л.С. Недостаточность комплекса V дыхательной цепи митохондрий, тип 2 (АТФ-синтазы), обусловленная мутациями в гене TMEM70: первое клиническое описание в РФ. Педиатрическая фармакология. $2018 ; 15$ (2): 175-178. doi: 10.15690/pf.v15i2.1874)

\section{ВВЕДЕНИЕ}

Характеристика заболевания:

этиология, патогенез

Болезни дыхательной цепи митохондрий - группа наследственных заболеваний, связанных с нару шением работы митохондрий вследствие мутационной блокады работы ферментов дыхательной цепи.
Аденозинтрифосфатсинтаза (АТФ-синтаза), называемая комплексом V дыхательной цепи митохондрий, - один из важнейших ферментов, участвующих в процессе окислительного фосфорилирования в клетке [1]. АТФ-синтаза, состоит из 16 субъединиц, две из которых (АТФ-6 синтаза и АТФ-8 синтаза) кодируются митохондриальными генами, а 14 - ядерными генами. Нарушение синтеза

Natal'ya V. Zhurkova, Nato D. Vashakmadze, Kirill V. Savost'anov, Aleksandr A. Pushkov, Artem M. Nesterov, Leyla S. Namazova-Baranova

National Scientific and Practical Center of Children's Health, Moscow, Russian Federation

\section{Mitochondrial Complex V (ATP-synthase) Deficiency Nuclear Type 2, Caused by Mutation in the TMEM70 Gene: the First Case in Russia}

Mitochondrial respiratory chain complex $V$ deficiency, type 2 is a rare hereditary disease developing due to mutations in TMEM70 (transmembrane protein 70) gene. Using massively parallel sequencing in patient with phenotype features, noncompaction of the left ventricular myocardium, and congenital heart disorder, we revealed mutations c.317-2A>G and c.578_579del in TMEM70 gene both in a heterozygous state. The mutations were confirmed by bi-directional automatic sequencing.

Key words: mitochondrial respiratory chain diseases, ATP- 6 synthetase, complex V mitochondrial respiratory chain, deficiency, noncompaction of the left ventricular myocardium, congenital heart disease, TMEM70.

(For citation: Zhurkova Natal'ya V., Vashakmadze Nato D., Savost'anov Kirill V., Pushkov Aleksandr A., Nesterov Artem M., NamazovaBaranova Leyla S. Mitochondrial Complex V (ATP synthase) Deficiency Nuclear Type 2, Caused by Mutation in the TMEM70 Gene: the First Case in Russia. Pediatricheskaya farmakologiya — Pediatric pharmacology. 2018; 15 (2): 175-178. doi: 10.15690/pf.v15i2.1874) 
АТФ приводит к повреждению митохондрий, нарушению функций клеток, в том числе в миокарде, и возникновению сердечной недостаточности [2]. Недостаточность АТФ-синтазы, обусловленная мутациями в гене TMEM70 (ОМІМ 612418), - редкое наследственное заболевание, возникающее в результате нарушения работы дыхательной цепи митохондрий [3-5]. Ген TMEM70, длиной 10347 пар нуклеотидов, расположенный в хромосомной области 8q21.11, кодирует митохондриальный трансмембранный белок TMEM70, длиной 260 аминокислотных остатков, молекулярной массой 28969 Да, играющий важную роль в биогенезе митохондриальной АТФазы. Мутации в этом гене вызывают развитие митохондриальной энцефалокардиомиопатии, наследуемой по аутосомно-рецессивному типу, возникающей вследствие дефицита АТФ-синтазы [1].

\section{Эпидемиология}

Впервые заболевание было описано в 2008 г. у пациента с кардиомиопатией, задержкой физического и психомоторного развития, фенотипическими особенностями [6]. В общей сложности на данный момент опубликовано описание 48 случаев данного заболевания [7], 4 из которых - в арабских [2], а 27 - в румынских семьях $[5,8]$.

\section{Клиническая картина}

Заболевание манифестирует с первых дней жизни. Дети рождаются с низкой массой тела. С возрастом задержка физического развития становится более выраженной. У всех детей описаны следующие особенности фенотипа: плоское лицо, плоское переносье, длинный фильтр, микрогнатия, ретрогнатия, широкая спинка носа, вздернутый нос, тонкая верхняя губа, низко посаженные диспластичные ушные раковины, пупочная и пахово-мошоночная грыжа $[3,6,7]$. Основные клинические проявления заболевания характеризуются задержкой физического и психомоторного развития, выраженной диффузной мышечной гипотонией, поражением сердечно-сосудистой системы, синдромом псевдообструкции кишечника. У большинства детей наблюдаются прогрессирующие неврологические нарушения вплоть до тяжелой лейкоэнцефалопатии и судорожного синдрома. У отдельных пациентов наблюдаются эпизоды энцефалопатии во время острых респираторных вирусных инфекций, инфекционных заболеваний, после физических и эмоциональных перегрузок. Со стороны сердечно-сосудистой системы описаны различные формы кардиомиопатии, включая синдром некомпактного миокарда левого желудочка и тяжелые аритмии (табл.) [6, 7]. У всех пациентов выявляются выраженный лактат-ацидоз, гипераммониемия, во время кризов гипераланиниемия и 3-метилглютаконовая ацидурия $[4,5]$.

\section{Дифференциальный диагноз}

Проводится с заболеваниями из группы органических ацидурий, нарушений митохондриального бетаокисления жирных кислот; болезнями дыхательной цепи митохондрий, обусловленных недостаточностью I II III, IV комплексов дыхательной цепи митохондрий; в связи с наличием у ребенка особенностей фенотипа и задержки физического и психомоторного развития с хромосомными заболеваниями, особенно с синдромами микроделеций и микродупликаций хромосом, включая микроделецию короткого плеча хромосомы 1 (1p36).
Таблица. 1. Показатели МРТ сердца с внутривенным контрастированием обследованного пациента

Table. 1. Parameters of cardiac MRI with intravenous contrasting of the examined patient

\begin{tabular}{|c|c|c|c|}
\hline \multicolumn{2}{|c|}{ Показатель } & \multirow{2}{*}{$\begin{array}{c}\text { Значение } \\
59,0\end{array}$} & \multirow{2}{*}{$\begin{array}{c}\text { Нормальные } \\
\text { значения } \\
\text { для возраста [6] } \\
-\end{array}$} \\
\hline LV EDV & мл & & \\
\hline LV EDV/BSA & мл/ $\mathrm{M}^{2}$ & 41,2 & $56-104$ \\
\hline LV ESV & мл & 34,0 & - \\
\hline LV ESV/BSA & мл/м ${ }^{2}$ & 23,7 & $16-40$ \\
\hline LV SV & мл & 25,0 & - \\
\hline LV SV/BSA & мл/ $\mathrm{M}^{2}$ & 17,4 & $36-72$ \\
\hline LV EF & $\%$ & 42,4 & $56-76$ \\
\hline RV EDV & мл & 49,0 & - \\
\hline RV EDV/BSA & мл/ $/ \mathrm{m}^{2}$ & 34,2 & $60-108$ \\
\hline RV ESV & мл & 26,0 & - \\
\hline RV ESV/BSA & мл/ $\mathrm{M}^{2}$ & 18,1 & $18-46$ \\
\hline RV SV & мл & 23,0 & - \\
\hline RV SV/BSA & мл/ $\mathrm{M}^{2}$ & 16,1 & $36-68$ \\
\hline RV EF & $\%$ & 46,9 & $54-70$ \\
\hline
\end{tabular}

Примечание. LV EDV - конечно-диастолический объем левого желудочка (ЛЖ), BSA - площадь поверхности тела, LV ESV — конечно-систолический объем ЛЖ, LV SV - ударный объем ЛЖ, LV EF — фракция выброса ЛЖ. RV- правый желудочек.

Note. LV EDV - left ventricular (LV) end diastolic volume, BSA body surface area, LV ESV - LV end-systolic volume, LV SV - LV stroke volume, LV EF — LV ejection fraction. RV — right ventricle.

\section{КЛИНИЧЕСКИЙ СЛУЧАЙ}

Представляем первое клиническое описание российского пациента с недостаточностью комплекса $\mathrm{V}$ дыхательной цепи митохондрий, тип 2, обусловленной мутациями ядерного генома, которая была диагностирована в лаборатории молекулярной генетики и клеточной биологии ФГАУ «НМИЦ здоровья детей» Минздрава РФ [9].

Мальчик, возраст 4 года, 4 мес. Наблюдается в Центре по поводу неклассифицируемой кардиомиопатии: «Гипертрофическая кардиомиопатия, необструктивная. Повышенная трабекулярность левого желудочка. Врожденный порок сердца: частичный аномальный дренаж левых верхнедолевых легочных вен, супракардиальная форма. Двустворчатый легочный клапан. Нарушение ритма сердца: мономорфная желудочковая экстрасистолия. ФК II по Ross. Нарушение психоречевого развития, вторичный миопатический синдром".

Семейный анамнез отягощен: брат пробанда умер на вторые сутки жизни. Ребенок от 6-й беременности, протекавшей без особенностей; от 3-х родов на 36-й неделе гестации путем планового кесарева сечения. На 32-й неделе гестации, по данным проведенной Эхо-КГ, обнаружена аномалия развития, мама ребенка направлена в НЦ CСХ им. А.Н. Бакулева для обследования - выявлена гипертрофия миокарда. Масса при рождении 2400 г, длина тела 48 см, оценка по APGAR 7/8 баллов. C первых дней жизни отмечалась плохая прибавка в массе тела, задержка моторного и психоречевого развития. До одного года наблюдался с диагнозом «Гипертрофическая кардиомиопатия необструктивная, умеренный стеноз 
легочной артерии". Ребенку исключена хромосомная патология - кариотип 46 XY, нормальный мужской; исключена болезнь Ниманна-Пика, тип С.

Впервые обследован в ФГАУ "НМИЦ здоровья детей" Минздрава РФ в возрасте 2,5 лет. При осмотре выявлены следующие особенности фенотипа: антимонголоидный разрез глаз, тонкие узкие брови, диспластичные низко посаженные ушные раковины, микрогнатия, широкая шея с крыловидными складками. Наблюдались задержка физического развития, выраженная диффузная мышечная гипотония, особенности поведения, задержка психоречевого развития. По данным УзИ сердца заподозрена кардиомиопатия: концентрическая кардиомиопатия миокарда желудочков сердца, локальное утолщение базального сегмента межжелудочковой перегородки и передней перегородочной стенки без обструкции выводных трактов желудочков, двустворчатый клапан легочной артерии без нарушения гемодинамики.

С целью оценки сердечного ритма и проводимости выполнен суточный холтеровский мониторинг ЭКГ: выявлена умеренно частая желудочковая экстрасистолия. В рамках дообследования проведена КТ органов грудной клетки с контрастированием: частичный аномальный дренаж верхней доли левого легкого через вертикальную вену в устье безымянной вены. По данным МРТ сердца с контрастным усилением подтвержден диагноз некомпактного миокарда левого желудочка с умеренным (42\%) снижением его сократительной способности (рис. 1).

MPT сердца с внутривенным контрастированием: качество исследования снижено вследствие малого возраста пациента и его пребывания в состоянии медикаментозного сна. Получены изображения в 2-, 3-, 4-камерной проекциях и в проекции по коротким

Рис. 1. Магнитно-резонансная томография сердца с контрастным усилением

Fig. 1. Cardiac magnetic resonance imaging with contrast enhancement

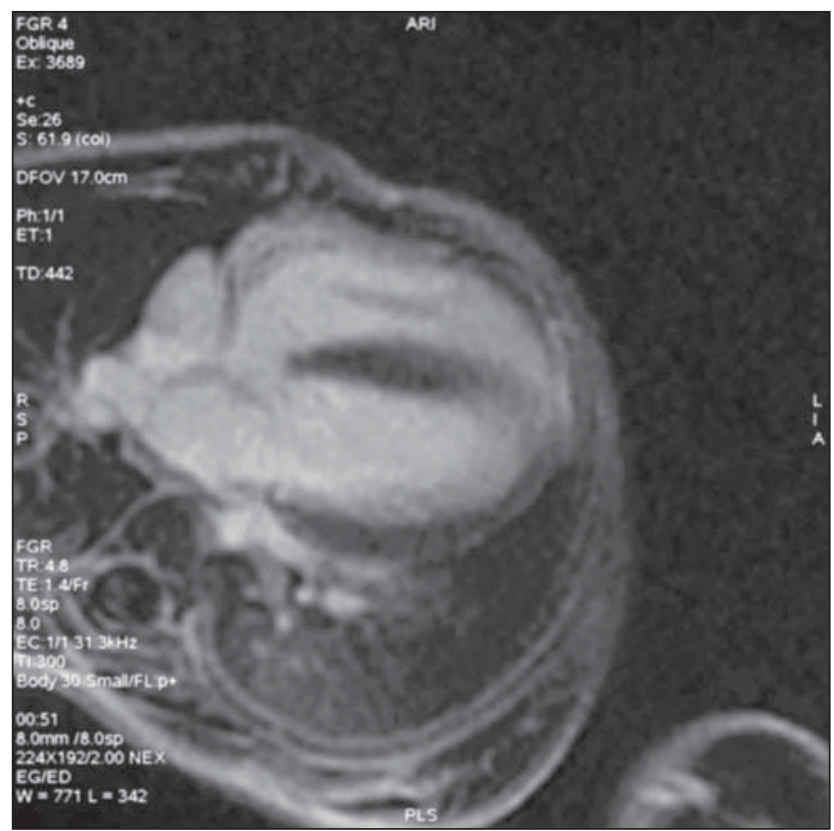

Примечание. МР картина гипертрофии миокарда левого желудочка с истончением компактного слоя и умеренным снижением сократительной активности.

Note. MR pattern of myocardial hypertrophy of the left ventricle with thinning of the compact layer and a moderate decrease in contractile activity. осям. Кино-режим: сократительная активность правого и левого желудочков умеренно снижена. Вдоль боковых и нижних стенок в среднем и верхушечном сегментах отмечаются часто расположенные разнонаправленные трабекулы. Максимальная толщина трабекулярного слоя до 9 мм, компактного - до 3 мм. Отмечается умеренное истончение и снижение сократительной способности компактного слоя миокарда вдоль трабекул. Толщина перегородки до 4-5 мм. T2-IR stir (Short tau inversion recovery, короткое время инверсии): патологических изменений в структуре миокарда не определяется. T1-IR: патологических изменений в структуре миокарда не определяется. Перфузия: участков замедления перфузии не определяется. Легочные вены от верхней доли левого легкого впадают в вертикальную вену, проходящую вдоль плевры и впадающую в область соединения левой подключичной и левой яремной вен. Раннее контрастирование: МР-признаков воспалительных изменений не определяется. Позднее отсроченное контрастирование (8-20 мин): МР-признаков структурных изменений не определяется. Перикард четкий, ровный, патологических скоплений жидкости не визуализируется. Вдоль диафрагмы выпот до 3 мм.

Учитывая, фенотипические особенности ребенка, наличие врожденного порока сердца и задержки психоречевого развития ребенку проведен хромосомный микроматричный анализ. Молекулярноцитогенетическое исследование геномной ДНК, выделенной из цельной венозной крови ребенка, проведено на микроматрицах высокого разрешения Affymetrix CytoScan HD (США). Делеций и дупликаций размером более 50 тыс пар нуклеотидов не обнаружено, анеуплоидий и аномальное число участков, протяженностью более 3000 тысяч пар нуклеотидов с потерей гетерозиготности, не выявлено.

Ребенку назначена и проведена тандемная массспектрометрия: показателей, свидетельствующих о развитии наследственных аминоацидопатий, дефектов митохондриального бета-окисления и органических ацидурий, не выявлено.

\section{ОБСУЖДЕНИЕ}

В связи с наличием у ребенка гипетрофической кардиомиопатии, снижением сократительной способности миокарда левого желудочка по данным МРТ и мышечной слабости с целью верификации диагноза проведено молекулярно-генетическое обследование с использованием технологии массового параллельного секвенирования, позволяющее проанализировать таргетные области 404 генов, мутации которых приводят к развитию генетически детерминированных кардиомиопатий и каналопатий синдромальной и несиндромальной природы [9].

В интроне 02 гена TMEM70 выявлена мутация c.317-2A $>$ G в гетерозиготном состоянии, приводящая к нарушению сплайсинга, тогда как в экзоне 03 гена TMEM70 - мутация c.578_579del (рис. 2) в гетерозиготном состоянии, приводящая к сдвигу рамки считывания p.Thr193Serfs*6. Мутации описаны ранее у пациентов с недостаточностью АТФ-синтетазы и неонатальной митохондриальной энцефалокардиомиопатией [4, 6]. Обе мутации, выявленные методом массового параллельного секвенирования, подтверждены методом прямого автоматического секвенирования по Сэнгеру.

Посредством проведенных исследований был установлен диагноз "Недостаточность комплекса V дыхательной цепи митохондрий, тип 2 (недостаточность АТФ- 
Рис. 2. Мутации с.317-2A>G и с.578_579del в гетерозиготном состоянии в гене TMEM70

Fig. 2. Mutations c.317-2A>G and c.578_579del in the heterozygous state in the TMEM70 gene
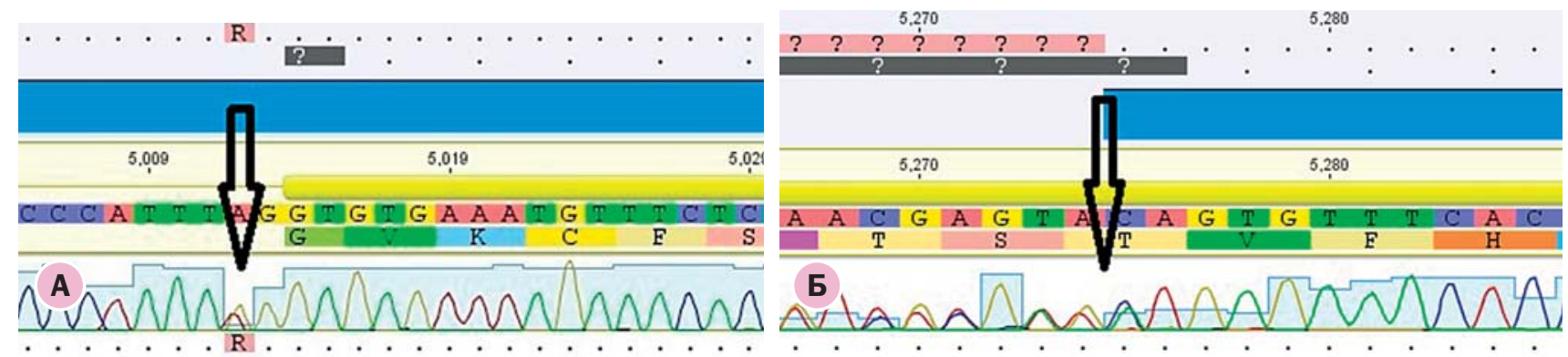

Примечание. Слева (А) хроматограмма сплайсинговой мутации с.317-2A>G в гетерозиготном состоянии. Справа (Б) хроматограмма делеции с.578_579del в гетерозиготном состоянии в гене TMEM70

Note. On the left (A), a chromatogram of c.317-2A>G splicing mutation in the heterozygous state. On the right (B), a chromatogram of c.578-579del deletion in the heterozygous state in the TMEM70 gene

синтетазы), аутосомно-рецессивный тип наследования". Ребенок получает метаболическую терапию (левокарнитин, убидекаренон), направленную на восстановление работы дыхательной цепи митохондрий, а также терапию хронической сердечной недостаточности, антиагрегантную и антиаритмическую терапию (каптоприл, метопролола сукцинат, ацетилсалициловую кислоту), на фоне чего отмечается положительная динамика: значительное повышение физической активности, уменьшение функционального класса сердечной недостаточности, значительное улучшение сократительной способности левого желудочка от $42 \%$ до нормы.

\section{ЗАКЛЮЧЕНИЕ}

Редкие наследственные заболевания встречаются в практике врачей практически всех специальностей. Верификация точного диагноза наследственного заболевания с использованием современных молекулярногенетических методов., особенно такого редкого как недостаточность комплекса $\mathrm{V}$ дыхательной цепи митохондрий, тип 2 (АТФ-синтазы), обусловленной мутациями в гене TMEM70, дает возможность назначить ребенку необходимую терапию, провести медико-генетическое консультирование семьи, при необходимости предложить пренатальную и/или предимплантационную диагностику, а также использовать другие профилактические методы высокотехнологичных репродуктивных технологий, направленные на снижение повторных случаев возникновения данного заболевания в отягощенной семье.

\section{ИСТОЧНИК ФИНАНСИРОВАНИЯ}

Не указан.

\section{КОНФЛИКТ ИНТЕРЕСОВ}

Л.С. Намазова-Баранова - получение исследовательских грантов от фармацевтических компаний Пьер Фабр, GenzymeEuropeB.V.,ОО0 «Астразене-каФармасьютикалз”, Gilead/PRA "Фармасьютикал Рисерч Ассошиэйтс СиАйЭс", "Bionorica", Teva Branded Pharmaceutical products R\&D, Inc/OОО «ППД Девелопмент (Смоленск)", "Сталлержен С. А.»/“Квинтайлс ГезмбХ" (Австрия).

Н.Д. Вашакмадзе читает лекции для компаний "Санофи Джензайм", "Шайер", "Биомарин".

Остальные авторы статьи подтвердили отсутствие конфликта интересов, о котором необходимо сообщить.

\section{ORCID}

Н.В. Журкова

http://orcid.org/0000-0001-6614-6115

н.Д. Вашакмадзе

http://orcid.org/0000-0001-8320-2027

К.В. Савостьянов

http://orcid.org/0000-0003-4885-4171

А.А. Пушков

http://orcid.org/0000-0001-6648-2063

A.M. Нестеров

http://orcid.org/0000-0003-3244-2391

л.С. Намазова-Баранова

http://orcid.org/0000-0002-2209-7531

\section{СПИСОК ЛИТЕРАТУРЫ}

1. Jonckheere Al, Smeitink JA, Rodenburg RJ. Mitochondrial ATP synthase: architecture, function and pathology. J Inherit Metab Dis. 2012;35(2):211-225. doi: 10.1007/s10545-011-9382-9.

2. Long $Q$, Yang $K$, Yang $Q$. Regulation of mitochondrial ATP synthase in cardiac pathophysiology. Am J Cardiovasc Dis. 2015;5(1):19-32. 3. Braczynski AK, Vlaho S, Müller K, et al. ATP synthase deficiency due to TMEM70 mutation leads to ultrastructural mitochondrial degeneration and is amenable to treatment. Biomed Res Int. 2015;2015:462592. doi: 10.1155/2015/462592.

4. Spiegel R, Khayat M, Shalev SA, et al. TMEM70 mutations are a common cause of nuclear encoded ATP synthase assembly defect: further delineation of a new syndrome. J Med Genet. 2011;48(3):177-182. doi: 10.1136/jmg.2010.084608.

5. Wortmann SB, Kluijtmans LA, Rodenburg RJ, et al. 3-Methylglutaconic aciduria - lessons from 50 genes and 977 patients. J Inherit Metab Dis. 2013;36(6):913-921. doi: 10.1007/ s10545-012-9579-6.

6. Cizkova A, Stranecky V, Mayr JA, et al. TMEM70 mutations cause isolated ATP synthase deficiency and neonatal mitochondrial

encephalocardiomyopathy. Nat Genet. 2008;40(11):1288-1290. doi: 10.1038/ng.246.

7. Magner M, Dvorakova V, Tesarova M, et al. Erratum to: TMEM70 deficiency: long-term outcome of 48 patients. J Inherit Metab Dis. 2015;38(3):417-426. doi: 10.1007/s10545-014-9774-8.

8. Kawel-Boehm N, Maceira A, Valsangiacomo-Buechel ER, et al. Normal values for cardiovascular magnetic resonance in adults and children. J Cardiovasc Magn Reson. 2015;17:29. doi: 10.1186/ s12968-015-0111-7.

9. Савостьянов К.В., Намазова-Баранова Л.С., Басаргина Е.Н., и др. Новые варианты генома российских детей с генетически обусловленными кардиомиопатиями, выявленные методом массового параллельного секвенирования // Вестник Российской академии медицинских наук. - 2017. - Т.72. - №4 - С. 242 253. [Savostyanov KV, Namazova-Baranova LS, Basargina EN, et al. The new genome variants in Russian children with genetically determined cardiomyopathies revealed with massive parallel sequencing. Annals of the Russian academy of medical sciences. 2017;72(4):242-253. (In Russ).] doi: 10.15690/vramn872. 